\title{
Improved Parameter-Estimation With MRI-Constrained PET Kinetic Modeling: A Simulation Study
}

\author{
Kjell Erlandsson, Maria Liljeroth, David Atkinson, Simon Arridge, Sebastien Ourselin, and
} Brian F. Hutton, Senior Member, IEEE

\begin{abstract}
Kinetic analysis can be applied both to dynamic PET and dynamic contrast enhanced (DCE) MRI data. We have investigated the potential of MRI-constrained PET kinetic modeling using simulated $\left[{ }^{18} \mathrm{~F}\right] 2-\mathrm{FDG}$ data for skeletal muscle. The volume of distribution, $V_{e}$, for the extra-vascular extra-cellular space (EES) is the link between the two models: It can be estimated by DCE-MRI, and then used to reduce the number of parameters to estimate in the PET model. We used a 3 tissue-compartment model with 5 rate constants (3TC5k), in order to distinguish between EES and the intra-cellular space (ICS). Time-activity curves were generated by simulation using the 3TC5k model for 3 different $V_{\mathrm{e}}$ values under basal and insulin stimulated conditions. Noise was added and the data were fitted with the $2 \mathrm{TC} 3 \mathrm{k}$ model and with the 3TC5k model with and without $V_{\mathrm{e}}$ constraint. One hundred noise-realisations were generated at 4 different noise-levels. The results showed reductions in bias and variance with $V_{e}$ constraint in the 3TC5k model. We calculated the parameter $k_{3}{ }^{\prime \prime}$, representing the combined effect of glucose transport across the cellular membrane and phosphorylation, as an extra outcome measure. For $k_{3}{ }^{\prime \prime}$, the average coefficient of variation was reduced from $52 \%$ to $9.7 \%$, while for $k_{3}$ in the standard 2TC3k model it was $3.4 \%$. The accuracy of the parameters estimated with our new modeling approach depends on the accuracy of the assumed $V_{e}$ value. In conclusion, we have shown that, by utilising information that could be obtained from DCE-MRI in the kinetic analysis of $\left[{ }^{18} \mathrm{~F}\right] 2$-FDG-PET data, it is in principle possible to obtain better parameter estimates with a more complex model, which may provide additional information as compared to the standard model.
\end{abstract}

Index Terms_FDG, kinetic modeling, PET/MRI.

Manuscript received July 15, 2015; revised October 02, 2015; accepted December 04, 2015. This work was supported by the EPSRC under Grant $\mathrm{EP} / \mathrm{K} 005278 / 1$. UCL/UCLH research is supported by the NIHR Biomedical Research Centers funding scheme.

$\mathrm{K}$. Erlandsson is with the Institute of Nuclear Medicine, University College London, London WC1E 6BT, U.K. (e-mail: k.erlandsson@ucl.ac.uk).

M. Liljeroth was with the Institute of Nuclear Medicine, University College London, London WC1E 6BT, U.K. She is now with University Hospital Southampton, Southampton SO16 6YD, U.K.

D. Atkinson is with the Centre for Medical Imaging, University College London, London WC1E 6BT, U.K.

S. Arridge is with the Department of Computer Science, University College London, London WC1E 6BT, U.K.

S. Ourselin is with the Centre for Medical Image Computing, University College London, London WC1E 6BT, U.K.

B. F. Hutton is with the Institute of Nuclear Medicine, University College London, London WC1E 6BT, U.K., and also with the Centre for Medical Radiation Physics, University of Wollongong, Wollongong NSW 2522, Australia.

Digital Object Identifier 10.1109/TNS.2015.2507444

\section{INTRODUCTION}

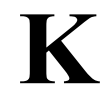
INETIC analysis of dynamic PET can be used for estimation of various physiological or biochemical parameters (see [1]-[4] for general summaries and [5][6] for FDG). The models used in these analyses are simplified versions of the true physiological and biochemical processes involved. Simplification is needed for reasons of numerical stability of the estimated parameters. Also dynamic MRI data can be used for estimation of physiological parameters. We wish to extend and improve the stability of conventional PET modeling through the use of specific kinetic MRI parameters. The reason behind this investigation is the recent introduction of combined PET/MRI scanners, which allow for simultaneous acquisition of PET and MRI data [7].

In dynamic contrast enhanced (DCE) MRI studies, Gd-based contrast agents can diffuse across the capillary walls but not across the cellular membrane. The data can be analysed using a model with one tissue-compartment (TC) and two rate constants, as shown in Fig. 1 [8]. We will refer to this model as a $1 \mathrm{TC} 2 \mathrm{k}$-model. The rate constants for forward and reverse transfer between blood and tissue are conventionally called $K^{\text {trans }}$ and $k_{e p}$, respectively, and their ratio is the volume of distribution of the extra-vascular extra-cellular space (EES) $\left(V_{\mathrm{e}}=K^{\text {trans }} / k_{\mathrm{ep}}\right)[8]$.

In PET studies, the most commonly used tracer is ${ }^{18} \mathrm{~F}$-labelled 2-fluoro-2-deoxy-D-glucose $\left(\left[{ }^{18} \mathrm{~F}\right] 2\right.$-FDG). This is a glucose analogue, which can be used for measuring the metabolic rate of glucose $\left(\mathrm{MR}_{\mathrm{glu}}\right)$. Most clinical $\left[{ }^{18} \mathrm{~F}\right] 2-\mathrm{FDG}$ studies consist of a single static PET scan, performed some time after the injection of the tracer. However, more accurate uptake values can be obtained by performing a dynamic scan and kinetic analysis.

After injection, $\left[{ }^{18} \mathrm{~F}\right] 2-\mathrm{FDG}$ is carried by the blood stream to different organs and tissues in the body. The tracer is extracted from the vascular to the extra-vascular space in the same way as glucose. In skeletal muscle this occurs by diffusion [9]. It is then transported from the EES across the cellular membrane to the intra-cellular space (ICS). This transport is facilitated by glucose transporters, some of which are insulin mediated [9]. Inside the ICS, $\left[{ }^{18} \mathrm{~F}\right] 2-\mathrm{FDG}$ can be phosphorylated to $\left[{ }^{18} \mathrm{~F}\right] 2-\mathrm{FDG}-6-\mathrm{PO}_{4}$ by the enzyme hexokinase. Phosphorylation is also the first step in the metabolism of glucose, but 


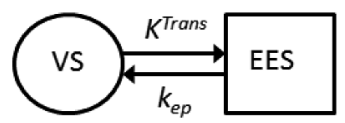

Fig. 1. DCE-MRI model with vascular space (VS) and extra-vascular extracellular space (EES).

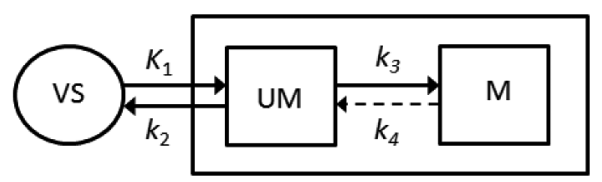

Fig. 2. Standard $\left[{ }^{18} \mathrm{~F}\right] 2-\mathrm{FDG}$ model with two tissue-compartments, representing un-metabolised (UM) and metabolised (M) tracer, respectively.

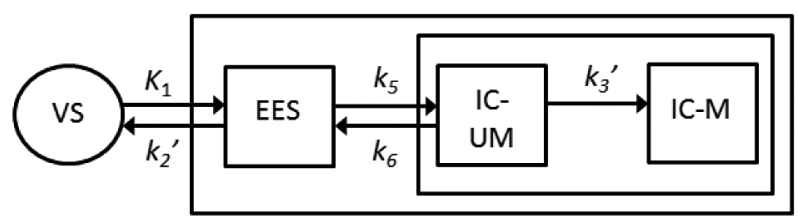

Fig. 3. $\left[{ }^{18} \mathrm{~F}\right] 2$-FDG model for skeletal muscle, proposed by Bertoldo et al. [10], including one EES compartment and two ICS compartments for un-metabolised (IC-UM) and metabolised tracer (IC-M), respectively. NB: The symbols for the rate constants are different from those in [10].

$\left[{ }^{18} \mathrm{~F}\right] 2-\mathrm{FDG}$ does not go any further along this metabolic pathway. In some tissues (e.g. brain), $\left[{ }^{18} \mathrm{~F}\right] 2-\mathrm{FDG}-6-\mathrm{PO}_{4}$ can be dephosphorylated back to $\left[{ }^{18} \mathrm{~F}\right] 2$-FDG by the enzyme glucose-6-phosphatase. This enzyme is not present in skeletal muscle and therefore no dephosphorylation occurs [9]. Free $\left[{ }^{18} \mathrm{~F}\right] 2-\mathrm{FDG}$ can be transported back across the cellular membrane to the EES and from there back to the blood stream.

Kinetic analysis of dynamic $\left[{ }^{18} \mathrm{~F}\right] 2$-FDG PET data was first applied to brain studies, and two different models were developed at an early stage: An irreversible model with 3 rate constants was proposed by Sokoloff et al. in 1977 [3], and a reversible model with 4 rate constants by Phelps et al. in 1979 [4] (see Fig. 2). Both models have two TCs, and we will refer to them as the $2 \mathrm{TC} 3 \mathrm{k}$ and $2 \mathrm{TC} 4 \mathrm{k}$ model, respectively. The parameter $k_{4}$ was introduced to represent dephosphorylation, which in the $2 \mathrm{TC} 3 \mathrm{k}$ model, is assumed to be negligible. In the $2 \mathrm{TC} 4 \mathrm{k}$ model, dephosphorylation is assumed to occur, although at a rate much lower than that of phosphorylation $\left(k_{4} \ll k_{3}\right)$. Neither of these models distinguish between the EES and the ICS, which corresponds to the implicit assumption that the rate of transport across the cellular membrane is much faster than the rate of phosphorylation, as this would lead to a steady state in the $\left[{ }^{18} \mathrm{~F}\right] 2-\mathrm{FDG}$ concentrations in EES and ICS from an early time point in the experiment.

In 2001, Bertoldo et al. proposed a model with 3 TCs and 5 rate-constants (3TC5k) for studying uptake of $\left[{ }^{18} \mathrm{~F}\right] 2-\mathrm{FDG}$ in skeletal muscle (Fig. 3) [10]. They argued that the transport of $\left[{ }^{18} \mathrm{~F}\right] 2-\mathrm{FDG}$ across the cellular membrane in skeletal muscle was not fast enough for the assumption mentioned above. This model is more realistic, containing one compartment for the EES and two for the ICS, for un-metabolised and metabolised tracer, respectively. However, with 5 parameters to estimate, there can be problems of parameter identifiability and numerical instability with noisy data.
In 2006, Bertoldo et al. presented a study, which combined the use of $\left[{ }^{18} \mathrm{~F}\right] 2$-FDG and the nonphosphorylatable glucose analog ${ }^{11} \mathrm{C}$-labeled 3-O-methyl-D-glucose $\left[{ }^{11} \mathrm{C}\right] 3-\mathrm{OMG}$ [11]. The data from the former tracer was analysed using the 3TC5k model mentioned above, while a $2 \mathrm{TC} 4 \mathrm{k}$ model was used for the latter tracer. The purpose of this study was to investigate the effect of insulin on the distribution of control among glucose delivery, transport, and phosphorylation in human skeletal muscle. The rate of delivery and transport were obtained from the $\left[{ }^{11} \mathrm{C}\right] 3-\mathrm{OMG}$ data, while the rate of phosphorylation was obtained from the $\left[{ }^{18} \mathrm{~F}\right] 2-\mathrm{FDG}$ data. The authors observed that, under insulin-stimulated conditions, the efficiency of glucose transport was increased by a factor of $\sim 6$ compared to fasting conditions, and thereby the uptake rate was constrained by the rate of delivery.

Another dual-tracer approach, with a two-injection scanning protocol, was proposed by Huang et al. [9] using $\left[{ }^{18} \mathrm{~F}\right] 2-\mathrm{FDG}$ in combination with the nonphosphorylatable glucose analog ${ }^{18} \mathrm{~F}$-labeled 6-fluoro-6-deoxy-D-glucose $\left(\left[{ }^{18} \mathrm{~F}\right] 6-\mathrm{FDG}\right)$. They used a $3 \mathrm{TC} 5 \mathrm{k}$ model in order to resolves the delivery, transport, and phosphorylation steps of the glucose metabolism in skeletal muscle. The model was based on Michaelis-Menten kinetics, so as to utilize information obtained from the competition between glucose and its radiolabeled analogs.

Zhang et al. [12] combined $\left[{ }^{15} \mathrm{O}\right]-\mathrm{H}_{2} \mathrm{O}$ PET with DCE-MRI in order to determine maps of the permeability-surface area product (PS) for the MRI contrast agent in tumours.

Here, we propose the use of information derived from DCE-MRI to constrain the kinetic model for $\left[{ }^{18} \mathrm{~F}\right] 2$-FDG PET in order to obtain more robust parameter estimation with a more realistic model. These data sets can be acquired simultaneously using an integrated PET/MRI scanner [7]. The key for linking the two models is the EES compartment, and therefore we need to use a 3TC-model for the PET data. This could also allow for estimation of more specific biological parameters, in addition to the standard parameters, which could be clinically relevant. We have evaluated the potential usefulness of this approach with simulated data for skeletal muscle.

\section{THEORY}

\section{A. Outcome Measures}

The main outcome measure in standard $\left[{ }^{18} \mathrm{~F}\right] 2$-FDG PET kinetic analysis is the macro-parameter $K_{i}$, which represents the combined effect of delivery, transport and metabolism. This parameter can be determined both with the standard $2 \mathrm{TC} 3 \mathrm{k}$ model (Fig. 2):

$$
K_{i}=\frac{K_{1} k_{3}}{k_{2}+k_{3}}
$$

and with the 3TC5k model (Fig. 3):

$$
K_{i}=\frac{K_{1} k_{5} k_{3}{ }^{\prime}}{k_{2}{ }^{\prime} k_{6}+k_{2}{ }^{\prime} k_{3}{ }^{\prime}+k_{5} k_{3}{ }^{\prime}}
$$

This parameter can be obtained directly from the impulse response function describing the system [2]. It corresponds to the 


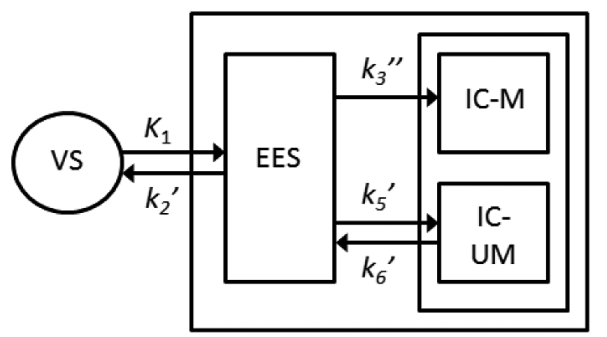

Fig. 4. Uncoupled $\left[{ }^{18} \mathrm{~F}\right] 2-\mathrm{FDG}$ model including the parameter $k_{3}{ }^{\prime \prime}$.

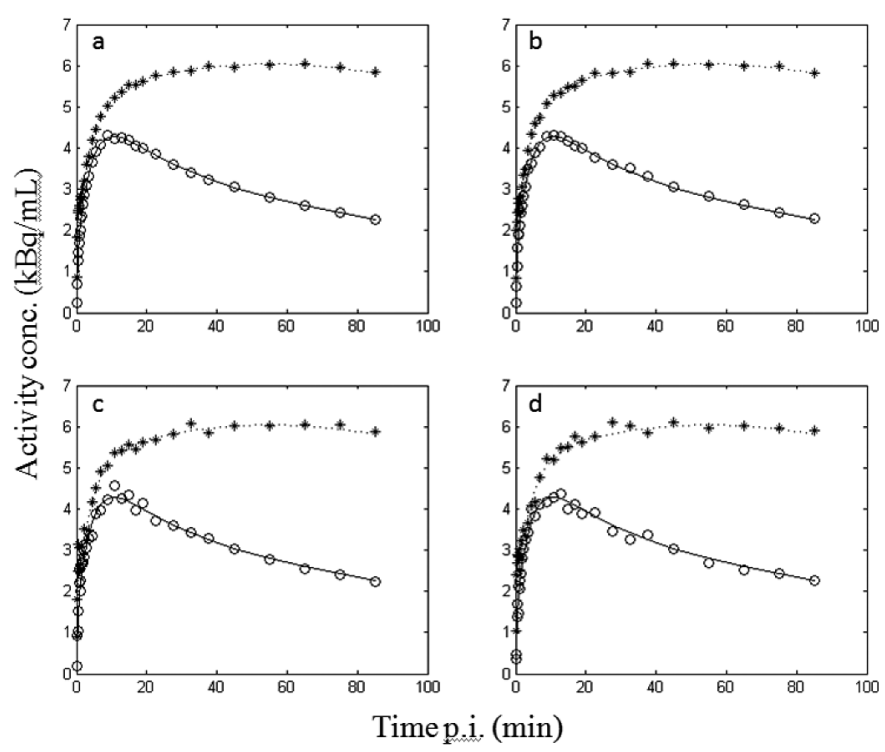

Fig. 5. Examples of simulated TACs with 4 different noise-levels for the basal (solid lines, circles) and insulin (dotted lines, stars) conditions.

rate of uptake of tracer from blood to tissue at steady state and is the basis for calculation of $\mathrm{MR}_{\mathrm{glu}}$.

We also define the parameter $k_{3}{ }^{\prime \prime}$, representing the combined effect of transport across the cellular membrane and phosphorylation:

$$
k_{3}^{\prime \prime}=\frac{k_{5} k_{3}{ }^{\prime}}{k_{6}+k_{3}{ }^{\prime}}
$$

The meaning of this parameter can be illustrated by the model in Fig. 4 , in which the 2 ICS compartments are uncoupled. $k_{3}{ }^{\prime \prime}$ is similar to $k_{3}$ in the standard model, but it is more specific, due to the explicit differentiation between EES and ICS. The models in Figs. 3 and 4 are in practice identical, the difference lies in the interpretation of the parameters. The rate constants of one model can be derived from those of the other one.

\section{B. Volume of Distribution}

The concept of "volume of distribution" has a slightly different meaning when used in the context of PET or MRI data. In MRI the term refers to the volume the physical space in which free contrast agent molecules can move around. In PET, the concept has been extended to include both free and bound tracer.
The total volume of distribution for a reversible tracer, described by a $2 \mathrm{TC} 4 \mathrm{k}$ model, is defined as follows [13]:

$$
V_{T}=\frac{K_{1}}{k_{2}}\left(1+\frac{k_{3}}{k_{4}}\right)
$$

The two terms correspond to free and bound tracer, respectively. In PET studies, $V_{T}$ is commonly used as an outcome measure to quantify binding of reversible tracers. It can be interpreted as the volume of plasma required to account for the amount of tracer present in a unit volume of tissue. In this paper, we will use the volume of distribution $V_{e}$, referring to the volume of the EES available for diffusion of either free tracer or contrast agent. This parameter is not dependent on extraction, transport or binding of the tracer or contrast agent.

Our basic assumption is that

$$
V_{e}=\frac{K_{1}}{k_{2}{ }^{\prime}}
$$

This implies that the transport between the vascular and extravascular spaces is symmetric, but the $k_{2}{ }^{\prime}$ parameter is influenced by the tissue-fraction effect, as the concentration of tracer in the EES cannot be measured directly. The same assumption was made by Huang et al. [9].

\section{New Modeling Approach}

We propose the use of the 3TC5k PET model (Fig. 3), constrained by the DCE-MRI estimated $V_{e}$ value. We have renamed the rate constants with respect to the nomenclature used by Bertoldo et al. [5]. The reason for this is that we want the rate constant with index 3 to represent the phosphorylation step, as in the standard model. Also, compared to this model, the new rate constants are the ones representing transport across the cellular membrane, which we therefore name $k_{5}$ and $k_{6}$. Some of the rate constants in Fig. 3 have been primed in order to distinguish them from rate constants in the standard model with the same index.

In order to use the model, the DCE-MRI data are analysed first, and $V_{e}$ is estimated and incorporated into the PET model as $k_{2}{ }^{\prime}=K_{1} / V_{e}$, thereby the number of parameters to estimate is reduced by 1 .

For comparison we also used the 3TC5k model without constraint. In this case, $V_{e}$ was estimated as one of the model parameter and $k_{2}{ }^{\prime}$ was obtained as above. This way we could restrict the range of $V_{\mathrm{e}}$ to $[0,1]$.

\section{Materials AND Methods}

\section{A. Evaluation}

To test our new modeling approach, we generated time-activity curves using the $3 \mathrm{TC} 5 \mathrm{k}$ model. Data were simulated for 3 different $V_{\mathrm{e}}$ values $(0.08,0.16$ and $0.24 \mathrm{~mL} / \mathrm{mL})$. The rate constants corresponding to $V_{e}=0.08$ were the ones determined experimentally by Bertoldo et al. [10], although slightly rounded-off for simplicity. For the other $V_{e}$ values, a scaling procedure was applied, so that $k_{2}{ }^{\prime}$ and $k_{5}$ were inversely proportional to $V_{e}$, and $k_{3}{ }^{\prime}$ and $k_{6}$ inversely proportional to $V_{i}=$ 
TABLE I

PARAMETER VALUES FOR SIMULATIONS USING THE 3TC5K MODEL UNDER BASAL CONDITIONS

\begin{tabular}{l|lll}
\hline Parameter & \multicolumn{3}{|c}{ Values } \\
\hline $\boldsymbol{V}_{\boldsymbol{e}}$ & 0.08000 & 0.16000 & 0.24000 \\
$\boldsymbol{V}_{\boldsymbol{b}}$ & 0.00300 & 0.00300 & 0.00300 \\
$\boldsymbol{K}_{\mathbf{1}}$ & 0.02800 & 0.02800 & 0.02800 \\
$\boldsymbol{k}_{\mathbf{2}}{ }^{\prime}$ & 0.35000 & 0.17500 & 0.11667 \\
$\boldsymbol{k}_{\mathbf{5}}$ & 0.05000 & 0.02500 & 0.01667 \\
$\boldsymbol{k}_{\mathbf{6}}$ & 0.04000 & 0.04382 & 0.04845 \\
$\boldsymbol{k}_{\mathbf{3}^{\prime}}$ & 0.03000 & 0.03287 & 0.03634 \\
$\boldsymbol{K}_{\boldsymbol{i}}$ & 0.00162 & 0.00162 & 0.00162 \\
\hline
\end{tabular}

TABLE II

Parameter VAlues for Simulations Using the 3TC5K MOdel Under INSULIN STIMULATED CONDITIONS

\begin{tabular}{l|lll}
\hline Parameter & \multicolumn{3}{|c}{ Values } \\
\hline $\boldsymbol{V}_{\boldsymbol{e}}$ & 0.08000 & 0.16000 & 0.24000 \\
$\boldsymbol{V}_{\boldsymbol{b}}$ & 0.01500 & 0.01500 & 0.01500 \\
$\boldsymbol{K}_{\mathbf{1}}$ & 0.02800 & 0.02800 & 0.02800 \\
$\boldsymbol{k}_{\mathbf{2}}{ }^{\prime}$ & 0.35000 & 0.17500 & 0.11667 \\
$\boldsymbol{k}_{\mathbf{5}}$ & 0.15000 & 0.07500 & 0.05000 \\
$\boldsymbol{k}_{\mathbf{6}}$ & 0.03000 & 0.03291 & 0.03644 \\
$\boldsymbol{k}_{\mathbf{3}}{ }^{\prime}$ & 0.06000 & 0.06582 & 0.07289 \\
$\boldsymbol{K}_{\boldsymbol{i}}$ & 0.00622 & 0.00622 & 0.00622 \\
\hline
\end{tabular}

$\left(1-V_{e}-V_{b}\right)$, the volume of distribution of the ICS ( $V_{b}$ is the tissue blood volume). This procedure was based on the tissue fraction effect, mentioned above, resulting in the same $K_{i}$ for all $V_{e}$ values. Simulations were done both for basal and insulin stimulated conditions. The parameters used are presented in Tables I-II.

Noise-free time-activity curves (TACs) were generated with the following time-frames: $9 \times 10$ and $3 \times 30 \mathrm{~s}, 3 \times 1,7 \times 2$, $4 \times 5$ and $5 \times 10 \mathrm{~min}$, with a total scanning time of $90 \mathrm{~min}$. Normally distributed noise was added to the TACs, with standard deviation $(\sigma)$ values based on the activity concentration $(A)$ and the frame length $(\Delta t)$ as follows:

$$
\sigma=c \sqrt{A / \Delta t}
$$

where $c$ is a proportionality constant, which was changed in order to obtain 4 different noise-levels. One hundred noise-realisations were generated at each noise-level. The data were fitted with the standard 2TC3k model, and with the 3TC5k model, with and without constraint. The mean value and standard deviation of the estimated parameters were calculated across noiserealisations. The data generation and the curve-fitting were done with the software package COMCAT [14] in Matlab R1013a (The Mathworks, Inc., Natick, MA).
TABLE III

ESTIMATED VALUES (mean $\pm \mathrm{SD}$ ) FOR THE 2TC3K-MODEL WITH $V_{\mathrm{e}}=0.08$, BASAL CONDITIONS

\begin{tabular}{|c|c|c|c|c|}
\hline & $\begin{array}{l}\text { Noise level } \\
1\end{array}$ & 2 & 3 & 4 \\
\hline$K_{1}$ & $\begin{array}{r}0.02248 \\
\pm 0.00043\end{array}$ & $\begin{array}{r}0.02265 \\
\pm 0.00094\end{array}$ & $\begin{array}{r}0.02248 \\
\pm 0.00139\end{array}$ & $\begin{array}{r}0.02255 \\
\pm 0.00180\end{array}$ \\
\hline$k_{2}$ & $\begin{array}{r}0.22573 \\
\pm 0.00527\end{array}$ & $\begin{array}{r}0.22735 \\
\pm 0.01146\end{array}$ & $\begin{array}{r}0.22571 \\
\pm 0.01748\end{array}$ & $\begin{array}{r}0.22665 \\
\pm 0.02236\end{array}$ \\
\hline$k_{3}$ & $\begin{array}{r}0.01968 \\
\pm 0.00023\end{array}$ & $\begin{array}{r}0.01965 \\
\pm 0.00050\end{array}$ & $\begin{array}{r}0.01966 \\
\pm 0.00080\end{array}$ & $\begin{array}{r}0.01964 \\
\pm 0.00099\end{array}$ \\
\hline$K_{\mathrm{i}}$ & $\begin{array}{r}0.00180 \\
\pm 0.00001\end{array}$ & $\begin{array}{r}0.00180 \\
\pm 0.00002\end{array}$ & $\begin{array}{r}0.00180 \\
\pm 0.00003\end{array}$ & $\begin{array}{r}0.00180 \\
\pm 0.00005\end{array}$ \\
\hline
\end{tabular}

TABLE IV

Estimated VALUES (mean \pm SD) FOR THE UNCONSTRAINED 3TC5K MODEL WITH $V_{\mathrm{e}}=0.08$, BASAL CONDITIONS

\begin{tabular}{|c|c|c|c|c|}
\hline & $\begin{array}{l}\text { Noise level } \\
1\end{array}$ & 2 & 3 & 4 \\
\hline \multirow[t]{2}{*}{$K_{1}$} & 0.02814 & 0.02855 & 0.02852 & 0.02862 \\
\hline & \pm 0.00080 & \pm 0.00170 & \pm 0.00247 & \pm 0.00309 \\
\hline \multirow[t]{2}{*}{$k_{2}^{\prime}$} & 0.35310 & 0.36191 & 0.36687 & 0.36943 \\
\hline & \pm 0.01843 & \pm 0.03878 & \pm 0.06285 & \pm 0.06978 \\
\hline \multirow[t]{2}{*}{$k_{5}$} & 0.05067 & 0.05366 & 0.05732 & 0.05900 \\
\hline & \pm 0.00629 & \pm 0.01299 & \pm 0.02564 & \pm 0.02610 \\
\hline \multirow[t]{2}{*}{$k_{6}$} & 0.04013 & 0.04414 & 0.04638 & 0.05189 \\
\hline & \pm 0.00935 & \pm 0.01770 & \pm 0.02974 & \pm 0.04647 \\
\hline \multirow[t]{2}{*}{$k_{3}{ }^{\prime}$} & 0.02909 & 0.02912 & 0.02727 & 0.02712 \\
\hline & \pm 0.00347 & \pm 0.00694 & \pm 0.00982 & \pm 0.01513 \\
\hline \multirow[t]{2}{*}{$k_{5} / k_{6}$} & 1.29869 & 1.34984 & 1.51485 & 1.67803 \\
\hline & \pm 0.16861 & \pm 0.46201 & \pm 0.69378 & \pm 1.21024 \\
\hline \multirow[t]{2}{*}{$K_{\mathrm{i}}$} & 0.00161 & 0.00158 & 0.00154 & 0.00146 \\
\hline & \pm 0.00004 & \pm 0.00019 & \pm 0.00023 & \pm 0.00043 \\
\hline
\end{tabular}

In order to determine the accuracy required in the $V_{\mathrm{e}}$ estimation, we performed a series of experiments, deliberately using incorrect $V_{\mathrm{e}}$ values. A $V_{\mathrm{e}}$ value of 0.16 was used to generate data, which were then analysed assuming $V_{\mathrm{e}}$ values with errors of $\pm 5 \%, \pm 10 \%$ and $\pm 20 \%$. One hundred noise-realisations were generated with the 2 nd of the 4 noise-levels mentioned above, and mean and SD values were calculated for the estimated parameters across noise-realisations.

\section{RESULTS}

The results from the simulations with $V_{\mathrm{e}}=0.08$, obtained with the $2 \mathrm{TC} 3 \mathrm{k}$ and the unconstrained and constrained $3 \mathrm{TC} 5 \mathrm{k}$ model, are presented in Tables III-V for basal conditions, and in Tables VI-VIII for insulin stimulated conditions.

For $K_{1}$, the 2TC3k model gives biased results, both under basal and insulin stimulated conditions. The 3 TC5k model gives accurate $K_{1}$-estimates, both with and without constraint, under basal conditions, while under insulin stimulated conditions, the constrained model gives better accuracy and precision, especially at higher noise-levels. The $k_{2}{ }^{\prime}$ values are better estimated with the constrained than with the unconstrained 3 TC5 $\mathrm{k}$ model, 
TABLE V

ESTIMATED VALUES (mean $\pm \mathrm{SD}$ ) FOR THE CONSTRAINED 3TC5K MODEL WITH $V_{\mathrm{e}}=0.08$, BASAL CONDITIONS

\begin{tabular}{|c|c|c|c|c|}
\hline & $\begin{array}{l}\text { Noise level } \\
1\end{array}$ & 2 & 3 & 4 \\
\hline$K_{1}$ & $\begin{array}{r}0.02806 \\
\pm 0.00054\end{array}$ & $\begin{array}{r}0.02830 \\
\pm 0.00121\end{array}$ & $\begin{array}{r}0.02801 \\
\pm 0.00163\end{array}$ & $\begin{array}{r}0.02801 \\
\pm 0.00216\end{array}$ \\
\hline$k_{2}^{\prime}$ & $\begin{array}{r}0.35077 \\
\pm 0.00671\end{array}$ & $\begin{array}{r}0.35370 \\
\pm 0.01506\end{array}$ & $\begin{array}{r}0.35012 \\
\pm 0.02032\end{array}$ & $\begin{array}{r}0.35016 \\
\pm 0.02703\end{array}$ \\
\hline$k_{5}$ & $\begin{array}{r}0.04982 \\
\pm 0.00181\end{array}$ & $\begin{array}{r}0.05068 \\
\pm 0.00306\end{array}$ & $\begin{array}{r}0.05101 \\
\pm 0.00541\end{array}$ & $\begin{array}{r}0.05307 \\
\pm 0.01517\end{array}$ \\
\hline$k_{6}$ & $\begin{array}{r}0.03936 \\
\pm 0.00473\end{array}$ & $\begin{array}{r}0.04183 \\
\pm 0.00827\end{array}$ & $\begin{array}{r}0.04319 \\
\pm 0.01519\end{array}$ & $\begin{array}{r}0.05112 \\
\pm 0.05413\end{array}$ \\
\hline$k_{3}{ }^{\prime}$ & $\begin{array}{r}0.02940 \\
\pm 0.00275\end{array}$ & $\begin{array}{r}0.03053 \\
\pm 0.00482\end{array}$ & $\begin{array}{r}0.03039 \\
\pm 0.00897\end{array}$ & $\begin{array}{r}0.03040 \\
\pm 0.01355\end{array}$ \\
\hline$k_{5} / k_{6}$ & $\begin{array}{r}1.27901 \\
\pm 0.11287\end{array}$ & $\begin{array}{r}1.24319 \\
\pm 0.16855\end{array}$ & $\begin{array}{r}1.30030 \\
\pm 0.41431\end{array}$ & $\begin{array}{r}1.35317 \\
\pm 0.50711\end{array}$ \\
\hline$\kappa_{\mathrm{i}}$ & $\begin{array}{r}0.00161 \\
\pm 0.00003\end{array}$ & $\begin{array}{r}0.00161 \\
\pm 0.00005\end{array}$ & $\begin{array}{r}0.00159 \\
\pm 0.00019\end{array}$ & $\begin{array}{r}0.00157 \\
\pm 0.00017\end{array}$ \\
\hline
\end{tabular}

TABLE VI

Estimated VALUES (mean $\pm \mathrm{SD}$ ) FOR THE 2TC3K MODEL with $V_{\mathrm{e}}=0.08$, INSULIN STIMULATED CONDITIONS

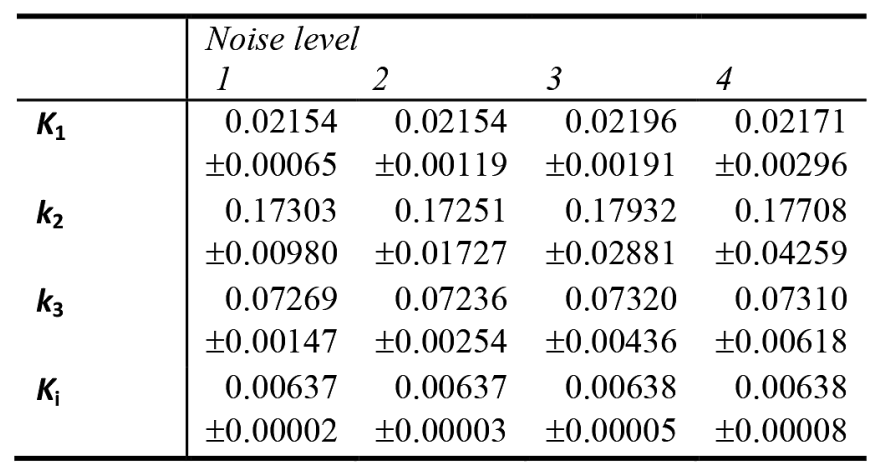

TABLE VII

ESTIMATED VALUES (mean \pm SD) FOR THE UNCONSTRAINED 3TC5K MODEL With $V_{\mathrm{e}}=0.08$, INSULIN STIMULATED CONDITIONS

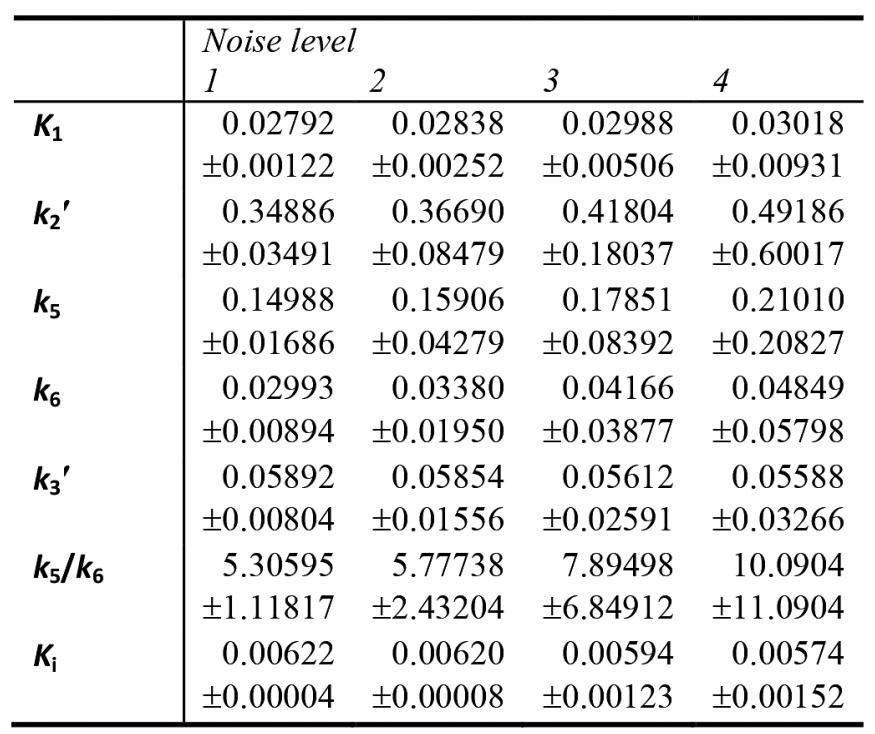

TABLE VIII

Estimated VAlues (mean \pm SD) FOR THE CONSTRAINED 3TC5K MOdEL WITH $V_{\mathrm{e}}=0.08$, INSULIN STIMULATED CONDITIONS

\begin{tabular}{|c|c|c|c|c|}
\hline & \multicolumn{4}{|c|}{ Noise level } \\
\hline & 1 & 2 & 3 & 4 \\
\hline \multirow{2}{*}{$K_{1}$} & 0.02794 & 0.02795 & 0.02827 & 0.02753 \\
\hline & \pm 0.00074 & \pm 0.00134 & \pm 0.00208 & \pm 0.00340 \\
\hline \multirow[t]{2}{*}{$k_{2}^{\prime}$} & 0.34929 & 0.34935 & 0.35339 & 0.34411 \\
\hline & \pm 0.00921 & \pm 0.01680 & \pm 0.02606 & \pm 0.04247 \\
\hline \multirow[t]{2}{*}{$k_{5}$} & 0.15057 & 0.15278 & 0.15380 & 0.17178 \\
\hline & \pm 0.00584 & \pm 0.01072 & \pm 0.02132 & \pm 0.07150 \\
\hline \multirow[t]{2}{*}{$k_{6}$} & 0.03060 & 0.03327 & 0.03625 & 0.06667 \\
\hline & \pm 0.00599 & \pm 0.01215 & \pm 0.02307 & \pm 0.15767 \\
\hline \multirow[t]{2}{*}{$k_{3}{ }^{\prime}$} & 0.06014 & 0.06152 & 0.06219 & 0.06881 \\
\hline & \pm 0.00682 & \pm 0.01364 & \pm 0.02314 & \pm 0.03806 \\
\hline \multirow[t]{2}{*}{$k_{5} / k_{6}$} & 5.06909 & 5.08602 & 5.76644 & 6.00358 \\
\hline & \pm 0.79241 & \pm 1.54515 & \pm 3.10696 & \pm 4.88915 \\
\hline \multirow[t]{2}{*}{$\kappa_{\mathrm{i}}$} & 0.00622 & 0.00621 & 0.00620 & 0.00612 \\
\hline & \pm 0.00003 & \pm 0.00007 & \pm 0.00016 & \pm 0.00065 \\
\hline
\end{tabular}

especially under insulin stimulated conditions, where the unconstrained model results in large bias and variance.

The $k_{5}$ and $k_{6}$ parameters are slightly better estimated with the constrained than with the unconstrained $3 \mathrm{TC} 5 \mathrm{k}$ model. However, the constrained model gives a clearly better estimation of the ratio $k_{5} / k_{6}$, especially under insulin stimulated conditions. This ratio is more important than the individual rate constants, as it determines the steady state concentration-ratio of free tracer in the EES and ICS.

In terms of $k_{3}{ }^{\prime}$, the constrained 3TC5k model gives slightly better accuracy than the unconstrained model. The $K_{\mathrm{i}}$ values obtained with the $2 \mathrm{TC} 3 \mathrm{k}$ model are biased, especially under basal conditions. The 3 TC5k model gives more accurate $K_{\mathrm{i}}$ estimates, with better accuracy and precision in the constrained than in the unconstrained case.

Fig. 6 shows the estimated $k_{3}$ and $k_{3}{ }^{\prime \prime}$ values for the 3 different $V_{\mathrm{e}}$ values, normalized to the true $k_{3}{ }^{\prime \prime}$ values. It can be seen that, with the standard 2TC3k model, the estimated $k_{3}$ values are close to the true $k_{3}{ }^{\prime \prime}$ values for large $V_{e}$ values under basal conditions. Otherwise the estimated values are lower. With the unconstrained 3TC5k model, the estimated $k_{3}{ }^{\prime \prime}$ values show large bias and variance. The constrained $3 \mathrm{TC} 5 \mathrm{k}$ model, on the other hand, gives much better $k_{3}{ }^{\prime \prime}$ estimates, under both basal and insulin stimulated conditions, although bias and variance increase at higher noise levels. The average coefficient of variation of $k_{3}{ }^{\prime \prime}$ was reduced from $52 \%$ to $9.7 \%$ by using the $V_{e}$ constraint, while for $k_{3}$ it was $3.4 \%$.

Results from the error estimation experiment are presented in Fig. 7 for $K_{1}$ and $k_{3}{ }^{\prime \prime}$. It can be seen that errors in $V_{\mathrm{e}}$ leads to errors in both parameters, although especially in $\mathrm{k}_{3}{ }^{\prime \prime}$. Interestingly, the effect on $K_{i}$ is a combination of the two.

\section{Discussion \& CONCLUSIONS}

In this paper we have proposed a novel approach for kinetic modeling of dynamic PET by incorporation of data derived from DCE-MRI. This allows for an increased complexity in the PET 

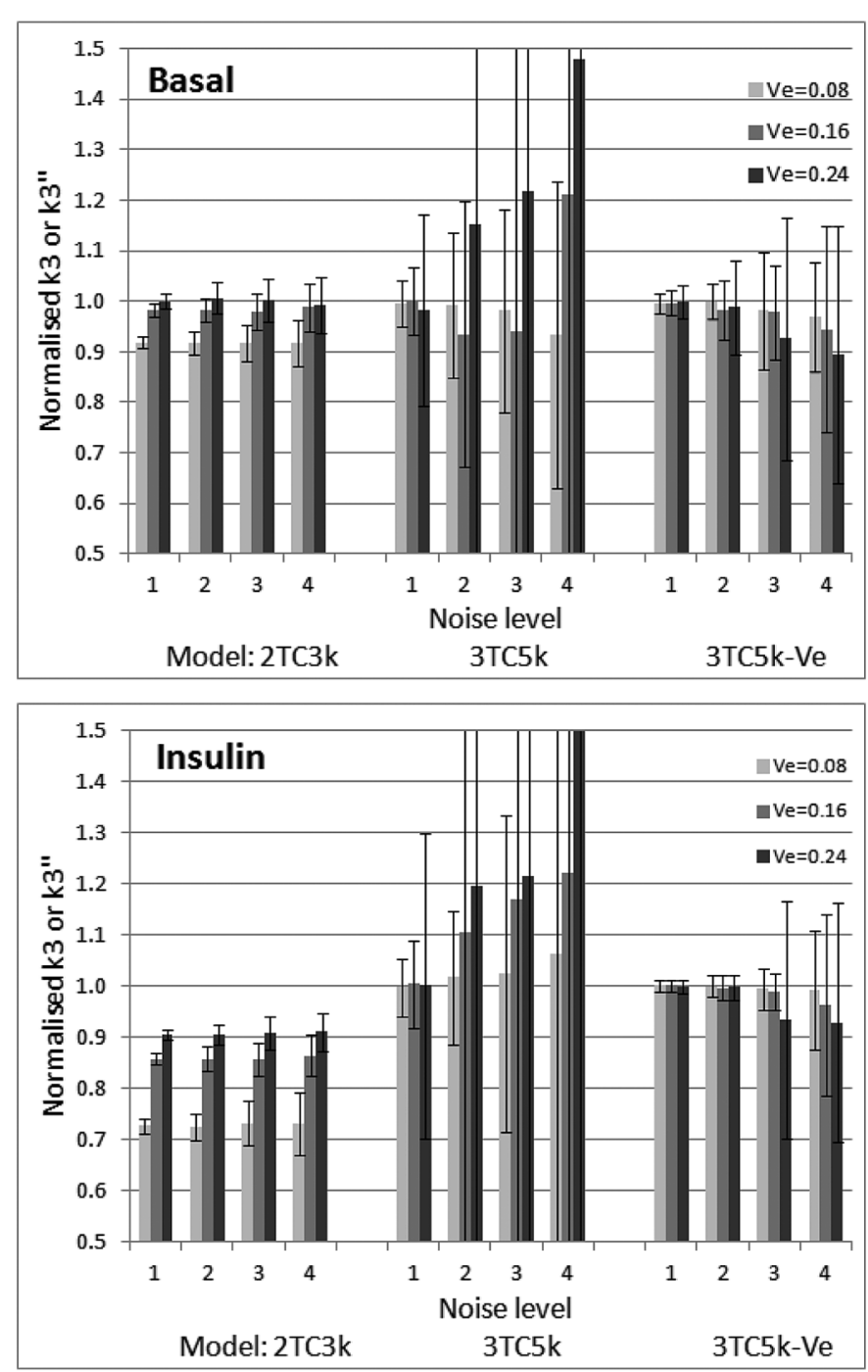

Fig. 6. Estimated values for $k_{3}$ or $k_{3}{ }^{\prime \prime}$, normalised to the true $k_{3}{ }^{\prime \prime}$ values (mean $\pm \mathrm{SD}$ ), for simulations with different $V_{\mathrm{e}}$-values; including $k_{3}$-values from the 2TC3k-model, and $k_{3 \mathrm{e}}{ }^{\prime \prime}$-values from the $3 \mathrm{TC} 5 \mathrm{k}$ model unconstrained and constrained ( $3 \mathrm{TC} 5 \mathrm{k}-V_{\mathrm{e}}$ ). Results are shown for 4 different noise-levels, for basal (top graph) and insulin stimulated conditions (bottom graph).

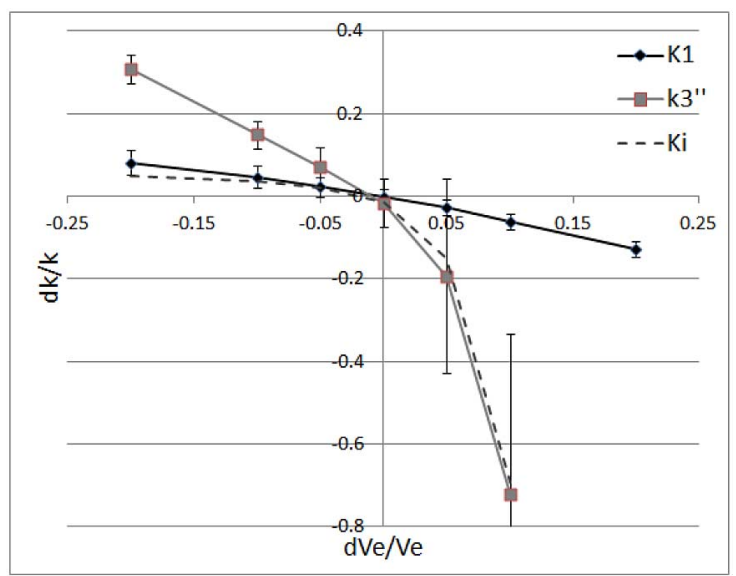

Fig. 7. Estimated relative error in $K_{1}$ and $k_{3}{ }^{\prime \prime}$ as a function of the relative error in $V_{\mathrm{e}}$. model, possibly providing more specific biological information. The key to this approach is the parameter $V_{\mathrm{e}}$.

The main outcome measure in $\left[{ }^{18} \mathrm{~F}\right] 2-\mathrm{FDG}$ kinetic analysis is usually $\mathrm{MR}_{\text {glu }}$, which can be calculated based on the macro-parameter $K_{i}$, which reflects the combined effects of delivery, transport and phosphorylation of glucose. A change in $K_{i}$ between 2 scans does not tell you in which of the 3 steps the change occurred. In some cases, however, it may be of interest to be able to distinguish between the different steps in the glucose metabolism [9]-[11]. E.g. the rate of glucose transport across the cellular membrane in skeletal muscle can change under the influence of insulin [11]. Although it may still be difficult to obtain good estimates of the parameters directly related to the transport step $\left(k_{5}\right.$ and $\left.k_{6}\right)$, we have shown that our new modeling approach allows for accurate estimation of the parameter $k_{3}{ }^{\prime \prime}$, which reflects the combined effect of transport and phosphorylation. This parameter is similar to $k_{3}$ in the standard $2 \mathrm{TC} 3 \mathrm{k}$ model, although more specific, since the $3 \mathrm{TC} 5 \mathrm{k}$ model includes a distinction between EES and ICS. We have shown that estimated $k_{3}$ values can in some cases be close to $k_{3}{ }^{\prime \prime}$, but are not so in general.

The simulations are based on a number of assumptions. Future work will include validation of these assumptions using real data. The advantages of simulated data are that it allows for comparison of the results with the true values and it also enables performing multiple experiments in order to determine the uncertainty in the estimated values.

Using simulated data, we have showed that, if $V_{\mathrm{e}}$ can be accurately derived from DCE-MRI, this parameter can be used as a constraint in a $3 \mathrm{TC} 5 \mathrm{k}$ model for $\left[{ }^{18} \mathrm{~F}\right] 2-\mathrm{FDG}$ in skeletal muscle, resulting in greater accuracy and precision of the estimated parameters as compared to the unconstrained modeling approach. This method could also be used with other tracers, e.g. $\left[{ }^{18} \mathrm{~F}\right] \mathrm{FLT}$, where it could be more beneficial.

\section{REFERENCES}

[1] R. E. Carson, "Tracer kinetic modeling in PET," in Positron Emission Tomography, D. L. Bailey, P. E. Valk, and M. N. Maisey, Eds. London, U.K.: Springer-Verlag, 2005, pp. 127-159.

[2] R. N. Gunn, S. R. Gunn, and V. J. Cunningham, "Positron emission tomography compartmental models," J. Cereb. Blood Flow Metab., vol. 21, pp. 635-52, Jun. 2001.

[3] M. Ichise, J. H. Meyer, and Y. Yonekura, "An introduction to PET and SPECT neuroreceptor quantification models," J. Nucl. Med., vol. 42, pp. 755-63, May 2001.

[4] K. Erlandsson, "Tracer kinetic modeling: Basics and concepts," in Basic Sciences of Nuclear Medicine, M. M. Khalil, Ed. Heidelberg, Germany: Springer, 2011, pp. 333-351.

[5] L. Sokoloff, M. Reivich, C. Kennedy, M. H. Des Rosiers, C. S. Patlak, and K. D. Pettigrew et al., "The [14C]deoxyglucose method for the measurement of local cerebral glucose utilization: Theory, procedure, and normal values in the conscious and anesthetized albino rat," $J$. Neurochem., vol. 28, pp. 897-916, May 1977.

[6] M. E. Phelps, S. C. Huang, E. J. Hoffman, C. Selin, L. Sokoloff, and D. E. Kuhl, "Tomographic measurement of local cerebral glucose metabolic rate in humans with (F-18)2-fluoro-2-deoxy-D-glucose: Validation of method," Ann. Neurol., vol. 6, pp. 371-88, Nov. 1979.

[7] B. J. Pichler, A. Kolb, T. Nagele, and H. P. Schlemmer, "PET/MRI: Paving the way for the next generation of clinical multimodality imaging applications," J. Nucl. Med., vol. 51, pp. 333-6, Mar. 2010.

[8] P. S. Tofts, G. Brix, D. L. Buckley, J. L. Evelhoch, E. Henderson, and M. V. Knopp et al., "Estimating kinetic parameters from dynamic contrast-enhanced T(1)-weighted MRI of a diffusable tracer: Standardized quantities and symbols," J. Magn. Reson. Imaging, vol. 10, pp. 223-32, 1999. 
[9] H. M. Huang, F. Ismail-Beigi, and R. F. Muzic, Jr., "A new Michaelis-Menten-based kinetic model for transport and phosphorylation of glucose and its analogs in skeletal muscle," Med. Phys., vol. 38, pp. 4587-99, 2011.

[10] A. Bertoldo, P. Peltoniemi, V. Oikonen, J. Knuuti, P. Nuutila, and C. Cobelli, "Kinetic modeling of [(18)F]FDG in skeletal muscle by PET: A four-compartment five-rate-constant model," Amer. J. Physiol. Endocrinol. Metab., vol. 281, pp. E524-36, Sep. 2001.

[11] A. Bertoldo, R. R. Pencek, K. Azuma, J. C. Price, C. Kelley, and C. Cobelli et al., "Interactions between delivery, transport, and phosphorylation of glucose in governing uptake into human skeletal muscle," Diabetes, vol. 55, pp. 3028-37, Nov. 2006.
[12] X. Zhang, Y. Petibon, A. Sitek, K. Takahashi, N. Alpert, and G. El Fakhri et al., "In-vivo Simultaneous DCE-MRI/O-15-water-PET," $J$. Nucl. Med., vol. 56, p. 644, 2015.

[13] R. B. Innis, V. J. Cunningham, J. Delforge, M. Fujita, A. Gjedde, and R. N. Gunn et al., "Consensus nomenclature for in vivo imaging of reversibly binding radioligands," J. Cereb. Blood Flow Metab., vol. 27, pp. 1533-9, Sep. 2007.

[14] R. F. Muzic, Jr. and S. Cornelius, "COMKAT: Compartment mode kinetic analysis tool,” J. Nucl. Med., vol. 42, pp. 636-45, Apr. 2001. 